\title{
Colonization of Rice Leaf Blades by an African Strain of Xanthomonas oryzae pv. oryzae Depends on a New TAL Effector That Induces the Rice Nodulin-3 Os11N3 Gene
}

\author{
Yanhua Yu, ${ }^{1,2}$ Jana Streubel, ${ }^{3}$ Sandrine Balzergue, ${ }^{4}$ Antony Champion, ${ }^{5}$ Jens Boch, ${ }^{3}$ Ralf Koebnik, ${ }^{1}$ \\ Jiaxun Feng, ${ }^{2}$ Valérie Verdier, ${ }^{1}$ and Boris Szurek ${ }^{1}$ \\ ${ }^{1}$ UMR 5096 IRD-CNRS-U. Perpignan, Laboratoire Génome et Développement des Plantes, 911 Avenue Agropolis BP 64501, \\ 34394 Montpellier Cedex 5, France; 2State Key Laboratory for Conservation and Utilization of Subtropical Agro-bioresources, \\ Key Laboratory of Ministry of Education for Microbial and Plant Genetic Engineering, College of Life Science and Technology, \\ Guangxi University, 100 Daxue Road, Nanning, Guangxi 530004, PR China; ${ }^{3}$ Department of Genetics, Martin-Luther- \\ University Halle-Wittenberg, D-06120, Halle (Saale), Germany; ${ }^{4}$ Unité de Recherche en Génomique Végétale (URGV) UMR \\ INRA 1165-CNRS 8114-UEVE 2, Rue Gaston Crémieux CP 570891057 Evry Cedex, France; ${ }^{5}$ UMR186 Résistance des \\ Plantes aux Bio-agresseurs, Institut de Recherche pour le Développement, BP 64501, 34394 Montpellier Cedex 5, France
}

Submitted 2 November 2010. Accepted 13 May 2011.

\begin{abstract}
African strains of Xanthomonas oryzae pv. oryzae contain fewer TAL effectors than Asian strains, and their contribution to pathogenicity is unknown. Systematic mutagenesis of $t a l$ genes was used to decipher the contribution of each of the eight TAL effector paralogs to pathogenicity of African $X$. oryzae pv. oryzae BAI3. A strain mutated in talC was severely affected in the production of disease symptoms. Analysis of growth in planta upon leaf-clip inoculation showed that mutant bacteria multiplied only at the site of inoculation at the apex of the leaf, suggesting a requirement for talC during colonization of vascular tissues. Such tissue-specific effect of a tal mutant is a novel phenotype, which has not yet been characterized in other xanthomonads. Microarray experiments comparing the host response of rice leaves challenged with $B A I 3^{R}$ vs. BAI $3^{R} \Delta$ talC were performed to identify genes targeted by TalC. A total of 120 upregulated and 21 downregulated genes were identified, among them Os11N3, which is a member of the MtN3/saliva family. Based on semiquantitative reverse transcription-polymerase chain reaction and $\beta$-glucuronidase reporter assays, we show that $0 s 11 N 3$ is directly upregulated by TalC and identify a TalC DNA target box within the $O \sin 3$ upstream sequence.
\end{abstract}

Phytopathogenic bacteria of the genus Xanthomonas cause severe diseases on many crop plants, including economically important plants such as rice, wheat, banana, beans, tomato, Citrus spp., and cotton. Common diseases found in nature include vascular wilt, cankers, leaf spots, fruit spots, leaf blight, and leaf streak. To colonize their host organisms, most Xanthomonas spp. evolved a highly conserved type III secretion sys-

Nucleotide sequence data for the entire 8,901-bp sequence carrying talC is available in GenBank under accession number 1465540 JN234375.

Corresponding author: B. Szurek: E-mail: Boris.Szurek@ird.fr

* The $e$-Xtra logo stands for "electronic extra" and indicates that one supplementary figure is published online and that Figures 1, 4, and 7 appear in color online. tem (T3SS) that injects a cocktail of type III effectors (T3E) into plant cells, in which they interfere with immune responses or facilitate nutritional or virulence processes of benefit for the pathogen. A recent review listed nearly 40 families of T3E from Xanthomonas spp. (White et al. 2009).

AvrBs3 from $X$. axonopodis pv. vesicatoria and PthA from $X$. citri subsp. citri are prototypes of an intriguing family of T3E (Bonas et al. 1989; Swarup et al. 1991). Homologs of these two proteins are only found in other Xanthomonas species and in Ralstonia solanacearum. Owing to their ability to reprogram the transcriptome of the host cells by mimicking eukaryotic transcription factors, AvrBs3/PthA-like proteins are also referred to as transcription activator-like (TAL) effectors (Yang et al. 2006). TAL effectors are characterized by a central protein domain comprised of a variable number of tandemlyrepeated near-identical modules of 34 or 35 amino acids. In addition, TAL effectors contain nuclear localization signals (NLS) and an acidic transcriptional activation domain (AAD) in their $\mathrm{C}$-terminal region. Because the $\mathrm{N}$ - and $\mathrm{C}$-terminal portions of the proteins are highly conserved, functional differences between members of the family are mainly due to the central repeat region. The number and order of repeats specify the virulence and avirulence activities of a given TAL effector (Boch and Bonas 2010). Recent results confirmed that the prototypic TAL effector AvrBs3 acts as a transcription factor that binds to specific DNA elements in the host cell nucleus and induces the expression of a distinct set of host genes. AvrBs3 was shown to bind directly to a so-called UPA (upregulated by AvrBs3) box in the promoter region of AvrBs3-dependently induced upa genes (Kay et al. 2007). One of the upa genes, upa20, encodes a basic helix-loop-helix transcription factor, which is sufficient to cause host-cell hypertrophy when expressed ectopically. The repeated modules of AvrBs3 are essential for DNA-binding of AvrBs3 and build up a unique type of DNA-binding domain. How this domain contacts DNA and determines specificity remained enigmatic until the recent discovery of the TAL effector's DNA recognition code (Boch et al. 2009; Moscou and Bogdanove 2009). The binding specificity is governed by so-called repeat-variable diresidues (RVD) at position 12 and 13, present in each module of the central 
protein domain. The number of repeated modules corresponds to the number of recognized base pairs. This knowledge of the recognition code now allows the prediction of target DNA boxes for TAL effectors.

A variety of TAL effectors are associated with biological effects and contribute to disease symptoms (White and Yang 2009). TAL effector-mediated gene induction leads, for instance, to developmental changes of the host plant, such as enhanced cell divisions in citrus canker and cell enlargement resulting in a hypertrophy of the tissue (Marois et al. 2002; Swarup et al. 1992). Other TAL effectors are required to establish the susceptibility of the host towards infection, although the molecular details of this interaction are largely unknown. When the responsible TAL effector is absent in a mutant bacterium, any susceptibility $(S)$ genes cannot be induced and disease cannot be established (White and Yang 2009). Hence, lack of susceptibility is reminiscent of a classic gene-for-gene resistance (Flor 1971). However, lack of susceptibility is typically a recessive trait, while classic gene-for-gene resistance follows a dominant segregation pattern. For example, Os $8 \mathrm{~N} 3$ was identified by comparative transcriptomics of susceptible rice challenged with $X$. oryzae pv. oryzae $\mathrm{PXO} 99^{\mathrm{A}}$ versus PXO99 ${ }^{\mathrm{A}}$ lacking the major virulence TAL effector gene pthXo1. Full virulence of $\mathrm{PXO}^{\mathrm{A}}$ was found to depend on PthXo1, which mediates the induction of the $S$ gene $O s 8 N 3$. Disease is impaired in RNAi lines in which $O s 8 N 3$ is knocked down (Yang et al. 2006). Os8n3 is a member of the $N 3$ gene family, which is found throughout the plant kingdom, and with related genes in mammals, insects, nematodes, and filamentous fungi (White and Yang 2009). Little is known about its role in disease with respect to promoting susceptibility to xylem-colonizing pathogenic bacteria. Three additional TAL effectors (pthXo2, pthXo3, and $a v r X a 7$ ) with major roles in virulence have been identified in field isolates of $X$. oryzae pv. oryzae (Hopkins et al. 1992; Yang and White 2004). They can each restore virulence to $\mathrm{PXO} 99^{\mathrm{A}}$ lacking $p t h X o 1$, but they do so without inducing $O s 8 N 3$ (Yang et al. 2006). It was speculated that these effectors target other members of the $N 3$ family (White and Yang 2009). Aside from pthXol, at least two TAL effector genes of PXO99 ${ }^{\mathrm{A}}$ have moderate effects on virulence, pthXo6 and pthXo7. They respectively mediate the induction of OsTFX1, a bZIP transcription factor gene, and OsTFIIA $\gamma 1$, a small subunit of the transcription factor IIA that compensates for the recessive $R$ gene $x a 5$ mutation in OsTFIIA $\gamma 5$ (Sugio et al. 2007). Intriguingly, the $S$ gene $O s 8 N 3$ is allelic to the recessive $R$ gene $x a 13$. Indeed, $x a 13$ differs from $O s 8 N 3$ by a substitution in the promoter region that prevents induction by PthXo1. Hence, resistance is due to impaired expression of Os8N3 (Chu et al. 2006b; Yang et al. 2006). xa5 is a missense mutant of the gene for the gamma subunit of the core transcription factor TFIIA (Lyer-Pascuzzi et al. 2008). It is hypothesized that the mutation provides protection against disease by blocking a function necessary for TAL effector-mediated $S$ gene induction (Bogdanove et al. 2010; White and Yang 2009). These two cases illustrate well the concept that resistance may result from a lack of susceptibility. On the other side, certain plant lines have evolved a sophisticated recognition strategy using dominant resistance $(R)$ gene promoters as molecular traps, taking advantage of the activity of TAL effectors (Bogdanove et al. 2010). Promoter activation by a certain TAL effector may lead to resistance gene induction and subsequent cell death or general resistance, as exemplified by pepper $B s 3$ and rice $\mathrm{Xa} 27$ resistance genes, which are induced by AvrBs3 and AvrXa27, respectively. In both cases, the susceptible alleles differ from the resistant ones by sequence variation in their promoter region, which impairs TAL effector recognition and binding (Gu et al. 2005; Römer et al. 2007).
Bacterial leaf blight (BLB) caused by $X$. oryzae pv. oryzae is one of the most devastating rice diseases worldwide (NinoLiu et al. 2006). X. oryzae pv. oryzae is a vascular pathogen, entering the plant through hydathodes or wounds. Upon entry in hydathodes, bacteria multiply in the epithem and gain access to the xylem, in which they disseminate systemically (Nino-Liu et al. 2006). In Africa, BLB has become emergent in most rice growing areas since the 1980s. Recently, we characterized new races originating from West Africa, highlighting substantial differences between Asian and African X. oryzae pv. oryzae strains (Gonzalez et al. 2007), which are also reflected in differences of their genome structures (V. Verdier and R. Koebnik, personal communication). Among other specific features, African strains were shown to harbor a reduced set of TAL effectors. A systematic mutagenesis was initiated in our laboratory, aiming at deciphering the contribution of each of the eight TAL effector paralogs of African $X$. oryzae pv. oryzae BAI3 to the pathogen's lifestyle and virulence. Several mutants were obtained, one of which (thereafter designated as talC) was severely affected in the production of disease symptoms on susceptible rice lines. This study reports on the functional characterization of talC, a new major virulence TAL effector of $X$. oryzae pv. oryzae, which targets $O s 11 N 3$, a member of the MtN3/saliva gene family.

\section{RESULTS}

\section{Systematic mutagenesis of tal genes \\ in $X$. oryzae pv. oryzae $\mathrm{BAI}^{\mathrm{R}}$ identifies a mutant with a strong defect in virulence.}

In order to analyze the function of each of the eight tal genes present in $X$. oryzae pv. oryzae $\mathrm{BAI} 3^{\mathrm{R}}$, we followed a systematic tal knock-out mutagenesis strategy. For this, we constructed a one-for-all integrative suicide plasmid (named pVO-155-tal) harboring a 206-bp DNA fragment encoding a highly conserved region downstream of the central repeat domain and upstream of the NLS and AAD (Fig. 1A). A single integrative recombination event, therefore, disconnects these two essential protein domains, resulting in truncated, functionally inactive TAL fragments. Because the 206-bp DNA fragment displays at least $90 \%$ of identity among X. oryzae tal genes, we assumed that each of the eight BAI ${ }^{\mathrm{R}}$ tal genes can potentially be targeted during mutagenesis. We conjugated pVO-155-tal into $X$. oryzae pv. oryzae $\mathrm{BAI} 3^{\mathrm{R}}$ and obtained 16 putative tal mutants. All 16 mutants were shown to result from pVO-155 integration into a tal gene, as indicated by nested polymerase chain reaction (PCR) analysis (based on the use of pVO-155- and tal- specific oligonucleotides located outside of the integration region). No transconjugants were obtained using the pVO-155 empty vector. Next, we performed pathogenicity assays by leaf-clip inoculation. Only one transconjugant (named $\mathrm{BAI} 3^{\mathrm{R}} \Delta$ talC) consistently led to a clear reduction of BLB symptoms, as shown by the measurement of lesion length on susceptible rice lines scored 2 weeks after leaf-clip inoculation (Fig. 1B). Sequencing of PCR amplicons from this mutant confirmed that $\mathrm{BAI} 3^{\mathrm{R}} \Delta$ talC was indeed inactivated in one of the eight $\mathrm{BAI} 3^{\mathrm{R}}$ tal genes (not shown).

\section{Molecular characterization of $\mathrm{BAI} 3^{\mathrm{R}} \Delta t a l C$.}

To decipher the identity of the affected tal gene, we examined the BAI $3^{\mathrm{R}} \Delta$ talC mutant by Southern blot hybridization. Genomic DNA was digested with BamHI, which cleaves outside of the central repeat region (at the ATG start codon and $149 \mathrm{bp}$ upstream of the stop codon) of almost all tal genes, and was probed with the avrXa7 3' region. Since tal genes mainly differ in the number and order of repeat modules in the central region, it is possible to distinguish different tal genes accord- 
ing to the size of their corresponding BamHI fragment. Comparing Bam HI-digested genomic DNA of wild-type $\mathrm{BAI} 3^{\mathrm{R}}$ with that of mutant strain $\mathrm{BAI} 3^{\mathrm{R}} \Delta$ talC revealed that a $3.7-\mathrm{kb}$ band was absent in $\mathrm{BAI} 3^{\mathrm{R}} \Delta$ talC (Fig. 2, lanes 1 and 2), suggesting that inactivation of the $3.7-\mathrm{kb}$ corresponding tal gene is responsible for the observed decreased virulence phenotype

\section{A}
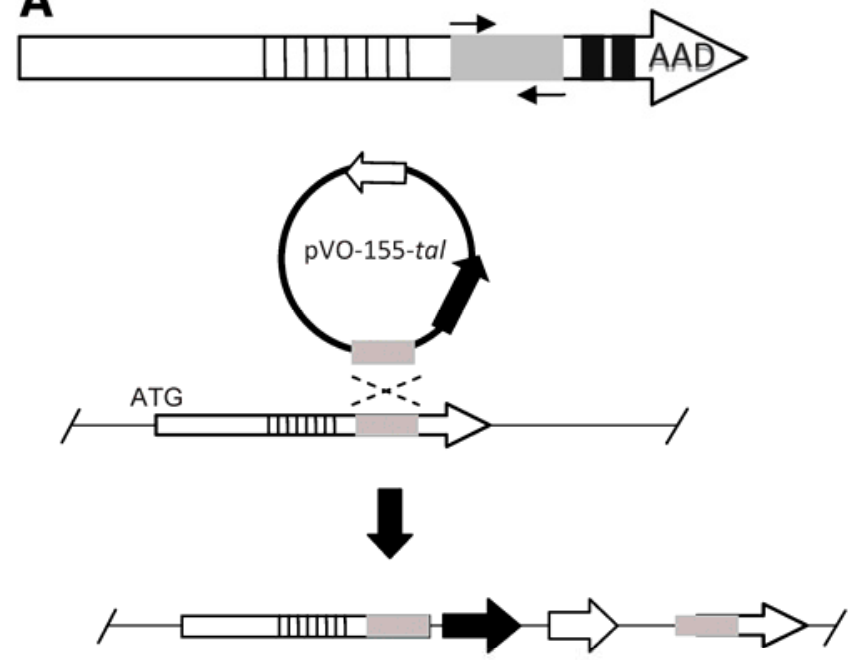

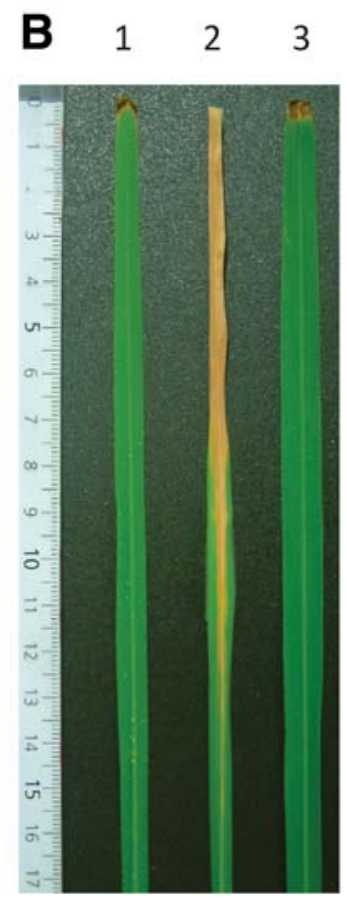

Nipponbare
123

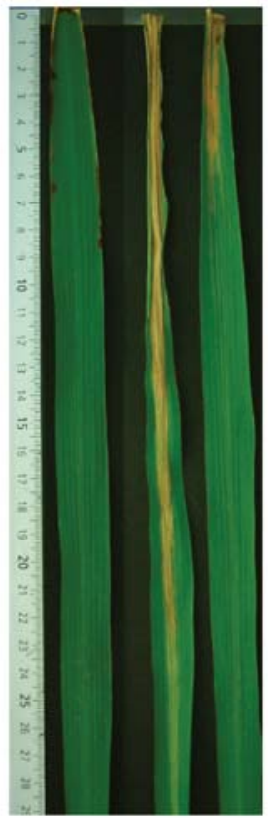

Azucena
Fig. 1. Phenotype of Xanthomonas oryzae pv. oryzae mutant strain BAI $3^{\mathrm{R}} \Delta$ talC upon leaf-clip inoculation. A, Schema of the strategy followed towards the systematic knock-out of tal genes in $X$. oryzae pv. oryzae $\mathrm{BAI} 3^{\mathrm{R}}$. A map of a typical tal gene is depicted, highlighting the repeat modules in the center and $\mathrm{C}$-terminal nuclear localization signals (black boxes) and an acidic activation domain. The conserved 206-bp sequence that was amplified from $\mathrm{BAI} 3^{\mathrm{R}}$ genomic DNA and cloned into pVO-155 yielding pVO-155-tal is represented in gray. White and black arrows in pVO-155 indicate nptII and uidA genes, respectively. B, Fourweek-old Nipponbare and Azucena lines were challenged with water (1), $X$. oryzae pv. oryzae wild-type strain $\mathrm{BAI} 3^{\mathrm{R}}(2)$, and $X$. oryzae pv. oryzae mutant strain BAI $3^{\mathrm{R}} \Delta$ talC (3) and were photographed 14 days after leafclip inoculation. This experiment was reproduced three times with similar results. of $\mathrm{BAI} 3^{\mathrm{R}} \Delta$ talC. We next constructed a BAI3 genomic DNA cosmid library in order to clone the corresponding tal gene. A total of $51 \mathrm{tal}$-containing cosmids were identified upon colony hybridization, and 18 cosmid clones were digested with BamHI and were analyzed by Southern blot hybridization using the avrXa $73^{\prime}$ region as probe. Cosmid $13 \mathrm{H} 5$ was found to carry a 3.7-kb BamHI fragment (Fig. 2, lane 3) and was digested with EcoRI for subcloning into pBBR1MCS-5 (Kovach et al. 1995). Restriction, PCR, and DNA sequence analysis identified one clone with a 8,901-kb EcoRI insert encompassing the complete coding sequence of the candidate tal gene with its native promoter (details below and in Figure 3A). This clone was named pBBR-13H5 and was used for complementation studies.

Transfer of pBBR-13H5 into BAI3 ${ }^{\mathrm{R}} \Delta$ talC restores virulence.

To demonstrate that the reduced virulence phenotype of $\mathrm{BAI} 3^{\mathrm{R}} \Delta$ talC is due to the inactivation of the identified tal candidate, plasmid pBBR-13H5 was conjugated into BAI ${ }^{\mathrm{R}} \Delta$ talC. Two independent transconjugants were subjected to pathogenicity assays using syringe-infiltration and leaf-clip inoculation. Infiltration of the parental strain $\mathrm{BAI} 3^{\mathrm{R}}$ resulted in watersoaked lesions located inside and around the area of inoculation, while $\mathrm{BAI} 3^{\mathrm{R}} \Delta$ talC was highly reduced in water-soaking (Fig. 4A, leaves 1 and 2). As shown in Figure 4A, transfer of pBBR-13H5 into BAI $3^{\mathrm{R}} \Delta$ talC restored water-soaking (leaves 4 and 5), in contrast to that of the empty vector pBBR1MCS-5 (leaf 3). In a more quantitative assay, leaf-clip inoculation also demonstrated the potential of pBBR-13H5 to restore virulence, albeit partially (Fig. 4B). To better understand why $\mathrm{BAI} 3^{\mathrm{R}} \Delta$ talC is limited in its capacity to lead to disease, we quantified bacterial populations within the top $15 \mathrm{~cm}$ at $0,4,8$, and 12 days after clip inoculation. Each leaf was cut into three 5-cm segments (A, B, and C), with A being close to the site of inoculation (Fig. 4C). Growth-curve profiles for $\mathrm{BAI} 3^{\mathrm{R}}$ and $\mathrm{BAI} 3^{\mathrm{R}} \Delta$ talC $\mathrm{pBBR} 13 \mathrm{H} 5$ were similar in each of the three leaf segments, while those for $\mathrm{BAI} 3^{\mathrm{R}} \Delta$ talC demonstrated that the $\mathrm{BAI} 3^{\mathrm{R}} \Delta$ talC population remained at the leaf apex in segment $\mathrm{A}$. Intriguingly, while $\mathrm{BAI} 3^{\mathrm{R}} \Delta$ talC had apparently lost the ability to colonize the rice leaf at sites distant to the inoculation area, bacteria were still able to multiply at near wild-type levels in leaf fragment $\mathrm{A}$. In contrast, no multiplication could be observed

\section{3}

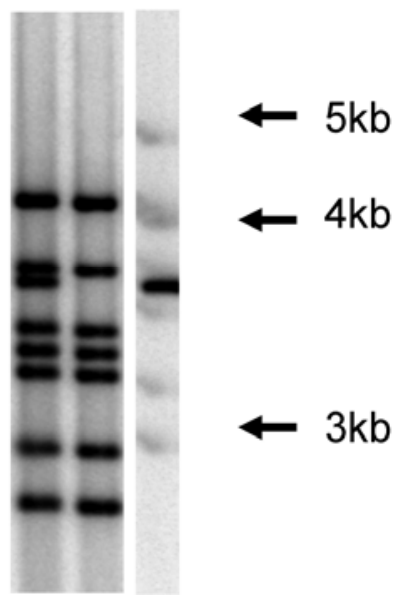

Fig. 2. Southern hybridization analysis of $\mathrm{BAI} 3^{\mathrm{R}} \Delta$ talC genomic DNA. Genomic DNA of Xanthomonas oryzae pv. oryzae strains $\mathrm{BAI} 3^{\mathrm{R}}$ (lane 1 ) and $\mathrm{BAI} 3^{\mathrm{R}} \Delta$ talC (lane 2) and DNA of cosmid clone 13H5 (lane 3) were digested with BamHI, were separated by gel electrophoresis, and were probed with a 725-bp 3' fragment of avrXa7. Size markers are indicated at the right side. 
upon leaf-clip inoculation of mutant strain $\mathrm{BAI} 3^{\mathrm{R}} \Delta h r c C$ with a defect in the T3SS (data not shown). Altogether, these data demonstrate that deletion of a tal in $\mathrm{BAI} 3^{\mathrm{R}} \Delta$ talC is associated with reduced virulence and loss of the capacity to spread through the leaf blade. Introduction of pBBR-13H5 into $\mathrm{BAI} 3^{\mathrm{R}} \Delta$ talC complemented for colonization along the rice leaf and partially for disease symptom development.

\section{talC encodes a new TAL effector}

with a unique order of 21.5 repeats.

Sequence analysis of the $8,901-\mathrm{kb}$ insert in pBBR-13H5 revealed an open reading frame of 3,825 bp encoding a predicted 1,274-amino acid (aa) protein with strong similarity to $X$. oryzae pv. oryzicola TAL effector proteins. Southern blot hybridization experiments showed that our tal of interest was the third one in terms of BamHI band size among the eight identified genes (Fig. 2, lane 1) and was therefore named talC. TalC is made up of a unique order of 21.5 repeats composed of mainly 34-aa modules and two 33-aa modules. As do almost all functional TAL effectors, TalC carries predicted NLS and an AAD in the C-terminal region. Immediately upstream and downstream of the talC locus are open reading frames encoding transposases of the IS1595 and ISXo17 families of insertion elements (IS) as well as a portion with similarity to IS5 transposases (Fig. 3A). To get insight into the evolutionary history of talC, we compared its nucleotide sequence (excluding the central repeat coding region) to those of different members of the tal family. Interestingly, as shown in a phylogenetic tree based on a maximum likelihood analysis (Fig. 5), talC clusters together with tal genes from Xanthomonas oryzicola pv. oryzicola. This is in agreement with previous data showing that $X$. oryzae pv. oryzae African strains are more closely related to $X$. oryzicola pv. oryzicola rather than to $X$. oryzae pv. oryzae strains originating from Asia (Gonzalez et al. 2007).

\section{TalC drives the induction}

of a member of the nodulin 3 (N3) gene family.

In order to identify rice genes directly targeted by TalC, we performed transcriptome analysis using the Affymetrix full genome array of rice. We compared RNA obtained from rice leaves challenged with $\mathrm{BAI} 3^{\mathrm{R}}$ vs. BAI $3^{\mathrm{R}} \Delta$ talC strains and harvested $24 \mathrm{~h}$ postinoculation of susceptible Nipponbare plants. Genes were analyzed according to fold increase, and some of the most strongly induced genes were validated using semiquantitative reverse transcription (sqRT)-PCR analysis (Table 1; Supplementary Fig. S1). Overall, 120 and 21 genes were found

A

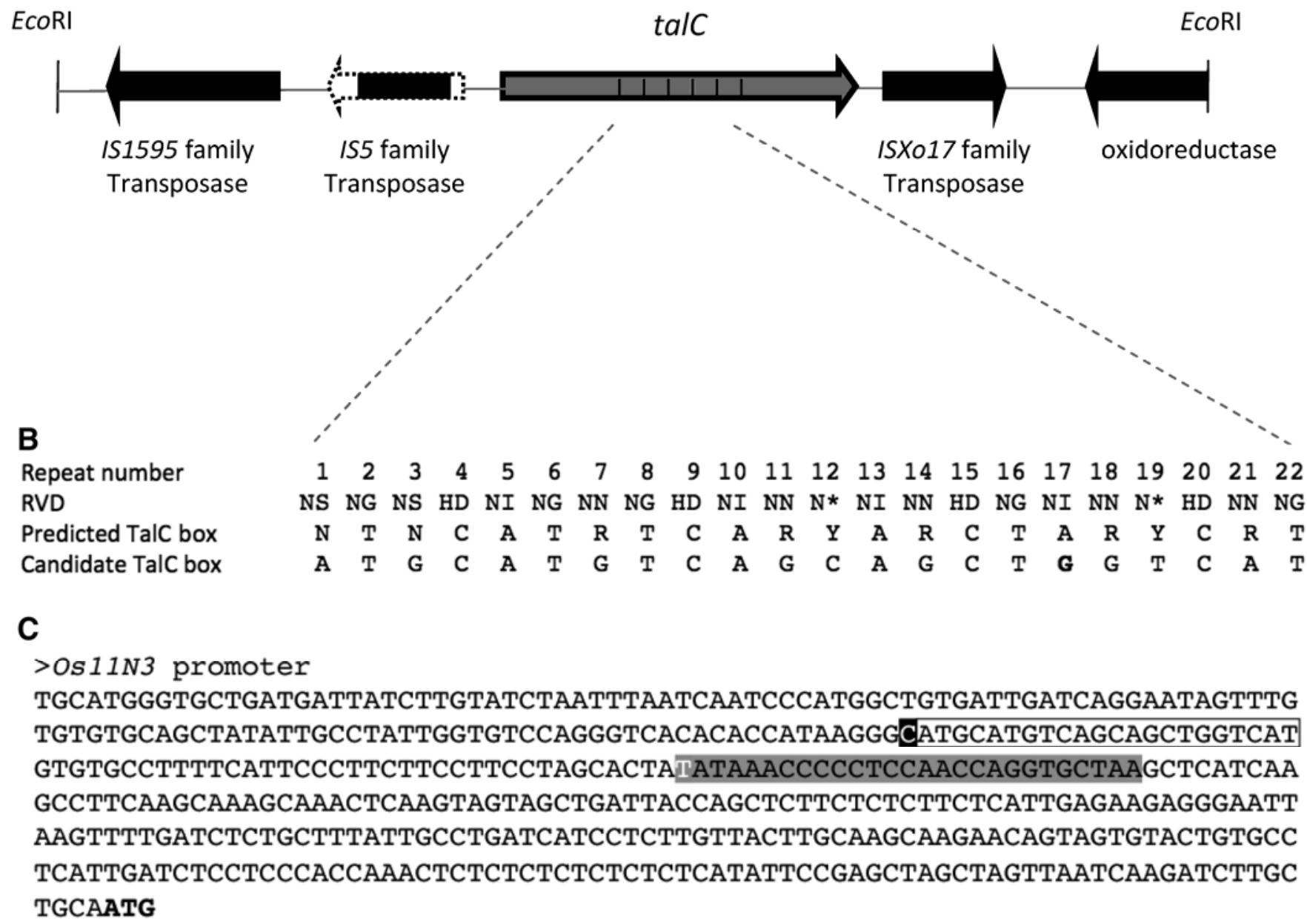

Fig. 3. Genetic organization of talC and candidate target DNA boxes. A, Annotation of the 9,005-kb EcoRI-fragment from pBBR-13H5 containing talC; upstream and downstream sequences include open reading frames (ORF) coding for transposases of the IS1595 and ISXo17 families, respectively. Immediately upstream of talC and to the $3^{\prime}$ end of the insert, portions of ORF with homology to IS5 transposases and to Xanthomonas oryzae pv. oryzae MAFF 311018 oxidoreductase (YP_452848.1), respectively, are also represented. B, Hypervariable amino acids at position 12 and 13 (RVD) of the 21.5 TalC repeats are aligned to the consensus target DNA box for TalC and candidate TalC box identified in the region upstream of $O s 11 N 3$. R, Y, and N stand for $\mathrm{G}$ or A, C or T, and A, T, C, or G, respectively. Bold font indicates the single position where the predicted recognized nucleotide differs from the one of the candidate box for TalC. C, The sequence of the Os11N3 upstream region is depicted with the candidate TalC box framed and the AvrXa7 box highlighted in solid gray (Römer et al. 2010). The start codon is indicated in bold font. The $5^{\prime}$ terminal nucleotide of each target box is indicated in white font. 
to be up- and down-regulated, respectively. Interestingly, the gene Os11g31190 (hereafter Os11N3), which displayed the highest fold induction, is a member of the MtN3/saliva gene family, which also includes the pthXol-dependently activated susceptibility gene $O s 8 N 3$ (Chu et al. 2006b; Yang et al. 2006). Moreover, the upstream region of $O s 11 N 3$ was recently shown to carry a functional DNA target box recognized by AvrXa7 of $X$. oryzae pv. oryzae PXO86 (Römer et al. 2010). We therefore considered $O \operatorname{silN3}$ to be a potentially good direct target of TalC and first focused on this gene. Os 11N3 is represented in the GenBank database by a full-length cDNA of 1,494 bp (accession AK101913) with five exons leading to a predicted coding sequence of $912 \mathrm{bp}$ (Fig. 6A). The increase in Os $11 \mathrm{N3}$ expression was confirmed by sqRT-PCR analysis, using oligonucleotides designed to specifically amplify a unique region in the $3^{\prime}$ untranslated region and cDNA prepared from total RNA of Nipponbare leaves upon infiltration of BAI $3^{\mathrm{R}}, \mathrm{BAI} 3^{\mathrm{R}} \Delta t a l C$, $\mathrm{BAI} 3^{\mathrm{R}} \Delta h r c C$, and water. Os $11 N 3$ was only induced by wildtype bacteria and not by inoculation of rice plants with water, with the T3SS-deficient strain BAI $3^{\mathrm{R}} \Delta h r c C$ (not shown) or with BAI3 ${ }^{\mathrm{R}} \Delta$ talC (Fig. 6B).

The region upstream of $O s 11 N 3$ is a direct target of TalC.

TAL effectors bind to DNA target boxes located upstream of target genes and induce their expression. The target box of a given TAL effector can be predicted from the order and identity of residues 12 and 13 of each repeat, referred to as RVD (Fig. 3A) (Boch et al. 2009; Moscou and Bogdanove 2009). Analysis of the $O \operatorname{s} 11 N 3$ promoter region identified a putative target box for TalC located 317 bp upstream of the predicted start codon (Fig. 3B). Our data thus suggest that TalC directly regulates Os11N3 expression upon binding to the target box in front of Os11N3. The major virulence TAL effector AvrXa7 was recently reported to drive the expression of $O s 11 N 3$ as well, and a target box residing $38 \mathrm{bp}$ downstream of the box of TalC was identified (Fig. 3C) (Römer et al. 2010). To test functionality, the predicted TalC box of Os11N3 as well as an optimized version according to the TalC RVD-binding specificities were introduced into the minimal pepper $B s 4$ promoter and were cloned in front of a uidA reporter gene. The reporter constructs were agroinfiltrated into Nicotiana benthamiana leaves in combination with talC or hax3, which are expressed under the control of a $35 S$ promoter. $\beta$-Glucuronidase (GUS) assays showed that the $B s 4$ promoter derivatives containing the TalC boxes were specifically recognized by TalC but not by Hax3 (Fig. 7A to C). Finally, a 341-bp fragment upstream of the Os11N3 coding sequence and including the predicted TalC box was cloned in front of the GUS reporter gene. Codelivery of this 341-bp fragment with talC led to even stronger GUS activity as compared with that when the target TalC box is embedded into the Bs4 minimal promoter (Fig. 7D). Altogether, this strongly suggests that Os $11 N 3$ is directly activated by TalC in planta.
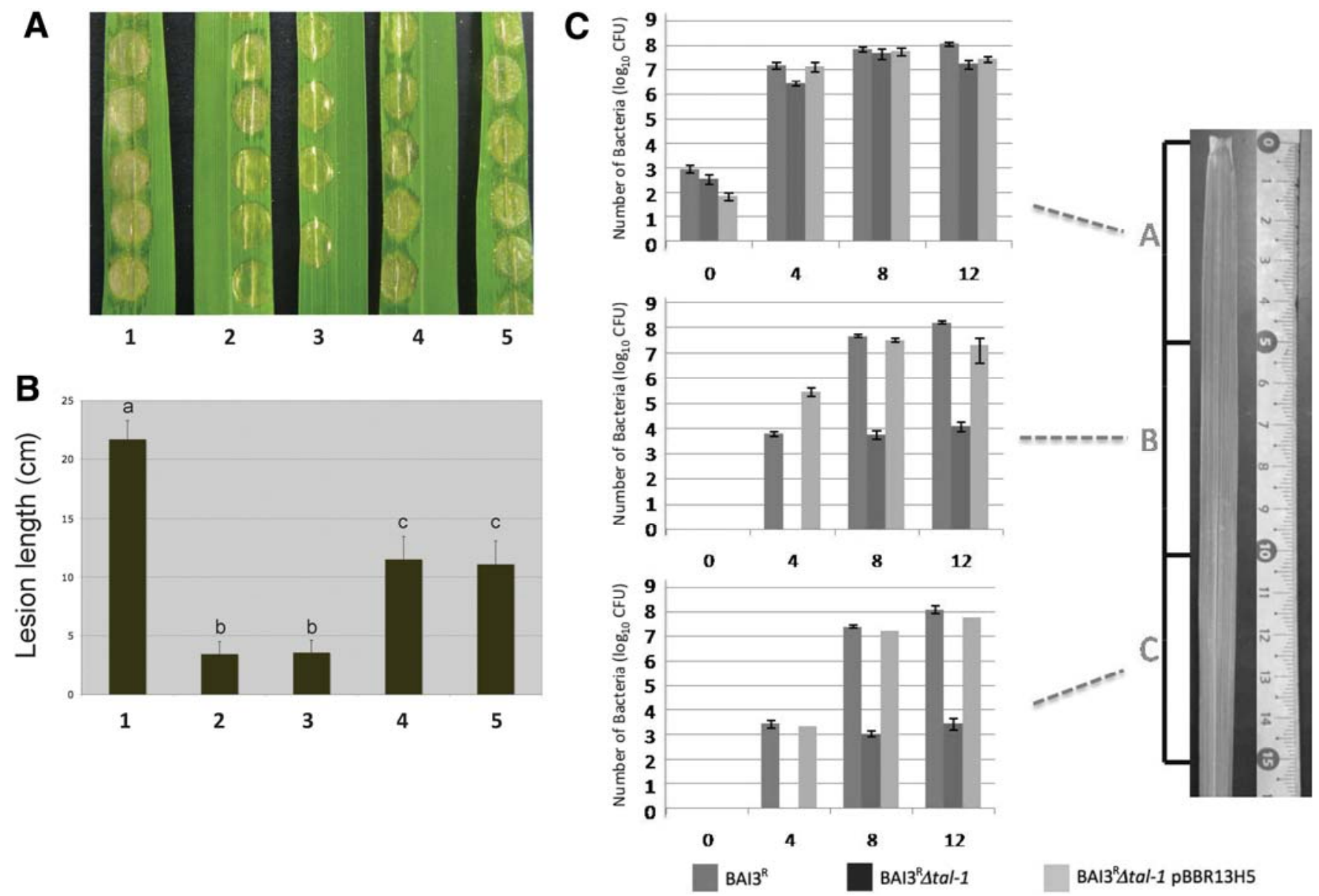

Fig. 4. Complementation analysis of mutant strain Xanthomonas oryzae pv. oryzae $\mathrm{BAI} 3^{\mathrm{R}} \Delta$ talC. A, Leaves of 3-week-old Nipponbare plants were infiltrated, using a needleless syringe, with $X$. oryzae pv. oryzae strains BAI $3^{\mathrm{R}}(1)$, BAI $3^{\mathrm{R}} \Delta$ talC (2), BAI3 ${ }^{\mathrm{R}} \Delta$ talC $(\mathrm{pBBR} 1 \mathrm{MCS}-5)(3)$, BAI ${ }^{\mathrm{R}} \Delta$ talC $(\mathrm{pBBR}-13 \mathrm{H} 5 \# 1)$ (4), and BAI3 ${ }^{\mathrm{R}} \Delta t a l C$ (pBBR-13H5\#2) (5). Leaves were photographed 5 days after inoculation. B, Lesion length was measured 14 days postinoculation of rice Azucena leaves with $X$. oryzae pv. oryzae strains BAI3 ${ }^{\mathrm{R}}(1), \mathrm{BAI}^{\mathrm{R}} \Delta t a l C(2)$, BAI3 ${ }^{\mathrm{R}} \Delta t a l C$ (pBBR1MCS-5) (3), BAI3 ${ }^{\mathrm{R}} \Delta t a l C$ (pBBR-13H5\#1) (4), and $\mathrm{BAI} 3^{\mathrm{R}} \Delta$ talC (pBBR-13H5\#2) (5). Means with the same letters are not statistically different based on a Tukey's honest significant difference test $(\alpha=0.05)$. C, Bacterial growth in 4-week-old rice Azucena leaves. Five-centimeter leaf segments A (proximal inoculation site), B, and C were scored at 0, 4, 8, and 12 days postinoculation. The experiment was repeated three times, using three leaves per tested condition. Error bars represent standard error. 
Because BAI3 is avirulent on IRBB7 lines containing the $a v r X a 7$-matching resistance gene $\mathrm{Xa7}$, we investigated the avrXa7-like activities of talC. To this end, pBBR-13H5 was conjugated into strain PXO99 ${ }^{\mathrm{A}}$, which is virulent on IRBB7. However, no gain of avirulence could be observed upon leafclip inoculation of IRBB7 leaves with PXO99 ${ }^{\mathrm{A}}$ (pBBR-13H5) (Table 2). Similarly, since BAI3 is also avirulent on IRBB4 and IRBB5 rice lines, we analyzed PXO99 ${ }^{\mathrm{A}}$ (pBBR-13H5) for a potential gain of avirulence, but again, transconjugants remained fully virulent. This suggests that, although both TalC and AvrXa7 target the susceptibility gene Os11N3, TalC does not trigger expression of the resistance gene $\mathrm{Xa}$.

\section{DISCUSSION}

This study reports on the functional analysis of TalC, a new member of the TAL-AvrBs3/PthA family of type III effectors. TalC was isolated from $X$. oryzae pv. oryzae BAI3, which originates in Burkina Faso in West Africa. While first reported in Africa in the 1980s, bacterial blight of rice is nowadays pre-

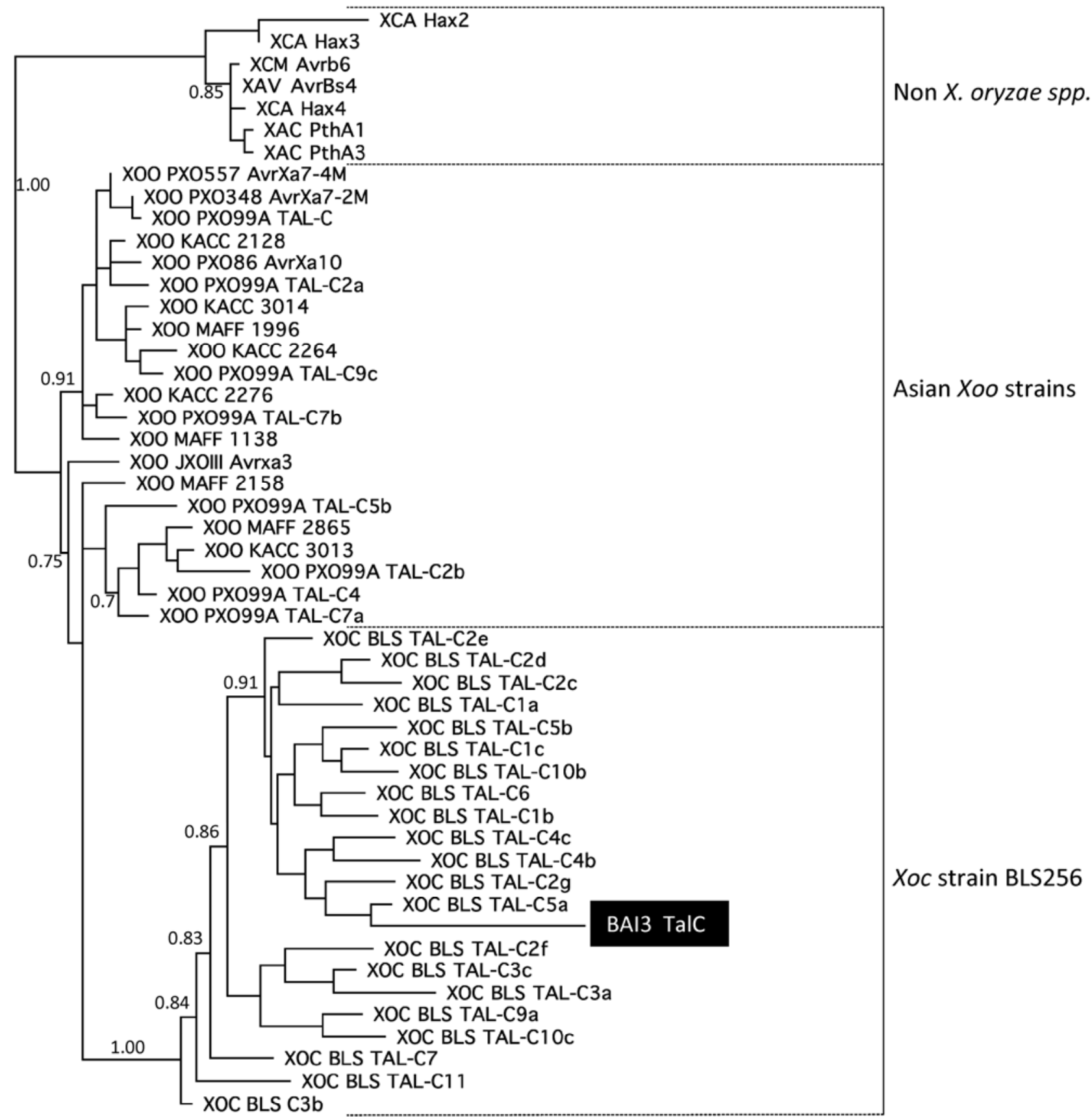

0.02

Fig. 5. talC clusters with tal genes of Xanthomonas oryzae pv. oryzicola. A neighbor-joining tree of Talc and related TAL effector proteins was constructed using ClustalW2 and approximate likelihood ratio test (aLRT)-PhyML. The branch length is proportional to divergence, and the 0.02 scale represents $2 \%$ change. Relevant aLRT support values are indicated as numbers $(0$ to 1$)$ at branching points. Protein names of Xanthomonas oryzae pathovars follow a pattern using an abbreviation of the species and pathovar, strain, and protein names. Xoo $=X$. oryzae pv. oryzae, MAFF $=$ strain MAFF $311018, \mathrm{KACC}=$ strain KACC10331, Xoc $=$ X. oryzae pv. oryzicola, BLS $=$ strain BLS256, Xav $=$ X. axonopodis pv. vesicatoria, Xca $=$ X. campestris pv. armoraciae, Xac $=$ X. axonopodis pv. citri, Xcm =X. campestris pv. malvacearum. The tree was rooted using protein sequences of the non-X. oryzae pathovars as outgroup. 
sent in most rice-producing West African countries and continues to spread along with the intensification of rice cultivation, thus causing a major concern for food security. Recently, we characterized new $X$. oryzae pv. oryzae races originating from West Africa (Gonzalez et al. 2007). A specific feature of African $X$. oryzae pv. oryzae strains, as compared with Asian strains, is a reduced number of tal genes. To gain insight into the pathogenicity of African X. oryzae pv. oryzae strains and to anticipate durable and broad resistance strategies, we evaluated the function of TAL effectors, some of which had been shown previously to be essential for $X$. oryzae pv. oryzae pathogenicity (White and Yang 2009).

\section{TalC is a new major virulence gene}

in $X$. oryzae pv. oryzae BAI3.

Systematic mutagenesis of tal genes in strain $\mathrm{BAI} 3^{\mathrm{R}}$ led to the generation of 16 mutants, only one of which was severely impaired in virulence. Molecular characterization revealed that the mutant was affected in one of the eight tal genes, referred to as talC. It remains to be investigated which tal genes were inactivated in the other mutants; however, none of them was impaired in virulence under our laboratory settings. Although we probably did not saturate the mutagenesis of all tal genes and some with detectable virulence function might have been missed, our data are consistent with the hypothesis that possibly all $X$. oryzae pv. oryzae strains, including those of African origin, strictly depend on only one or two members of the tal effector gene family for pathogenicity (Yang and White 2004). Inactivation of talC dramatically reduced lesion length (Fig. 1B) and water soaking (Fig. 4A), indicating that talC is a major virulence gene in $X$. oryzae pv. oryzae BAI3. Indeed, these results are reminiscent of pthXo1, pthXo2, pthXo3, and avrXa7, which encode major virulence determinants in $X$. oryzae pv. oryzae strains $\mathrm{PXO}^{\mathrm{A}}, \mathrm{JXO1}^{\mathrm{A}}, \mathrm{PXO61}$, and

Table 1. Fold increase and database matches for top 10 target sequences

\begin{tabular}{llllll}
\hline Rank $^{\mathbf{a}}$ & \multicolumn{1}{c}{ Probe set ID } & \multicolumn{1}{c}{ code AGI } & Ratio $^{\mathbf{b}}$ & $\boldsymbol{P}_{\text {value }}{ }^{\mathbf{c}}$ & RT-PCR $^{\mathbf{e}}$ \\
\hline 1 & Os.4974.1.S1_at & gb|AK101913.1 & 7.34 & $0.00^{\mathrm{E}}+0$ & Os11N3 nodulin MtN3 family protein \\
2 & Os.4974.1.S1_X_at & & 6.76 & $0.00^{\mathrm{E}}+0$ & \\
3 & Os.57323.1.S1_at & gb|AK111303.1 & 4.89 & $0.00^{\mathrm{E}}+0$ & HLH DNA-binding domain containing protein \\
4 & Os.9823.1.S1_at & gb|AK061798.1 & 3.01 & $0.00^{\mathrm{E}}+0$ & Cyclase family protein \\
5 & Os.4020.1.S1_at & gb|AK059636.1 & 2.68 & $0.00^{\mathrm{E}}+0$ & Oxidoreductase, aldo/keto reductase \\
6 & Os.17271.1.S1_at & gb|AK059809.1 & 2.54 & $0.00^{\mathrm{E}}+0$ & Citrate-binding protein precursor \\
7 & Os.55065.1.S1_at & gb|AK107405.1 & 2.5 & $0.00^{\mathrm{E}}+0$ & DNA binding protein \\
8 & OsAffx.13648.1.S1_a & tigr|9632.m00293 & 2.49 & $0.00^{\mathrm{E}}+0$ & Subtilisin homologue \\
9 & OsAffx.16605.1.S1_at & tigr|9635.m0377 & 2.12 & $0.00^{\mathrm{E}}+0$ & Cytochrome P450 51 \\
10 & Os.6043.1.S1_at & gb|AB040744.1 & 2 & $0.00^{\mathrm{E}}+0$ & Basic helix-loop-helix family protein \\
\hline
\end{tabular}

${ }^{\text {a }}$ Probe set references were ranked according to the fold increase of average value of the three replicates with BAI $3^{\mathrm{R}}$ compared with the average value of the three replicates with $\mathrm{BAI} 3^{\mathrm{R}} \Delta t a l C$.

${ }^{\mathrm{b}} \mathrm{Log}_{2}$ ratio of treatment with Xanthomonas oryzae pv. oryzae BAI3 ${ }^{\mathrm{R}}$ versus the value for treatment with $X$. oryzae pv. oryzae $\mathrm{BAI} 3^{\mathrm{R}} \Delta$ talC.

c A gene is declared differentially expressed if the Bonferroni $P$ value is less than 0.05 .

d Similarity matches were provided at the PLEXdb database.

e Semiquantitative reverse transcription-polymerase chain reaction $(\mathrm{RT}-\mathrm{PCR})$ was performed to validate gene expression. $+=$ TalC-dependent gene expression was confirmed; nd = not tested.
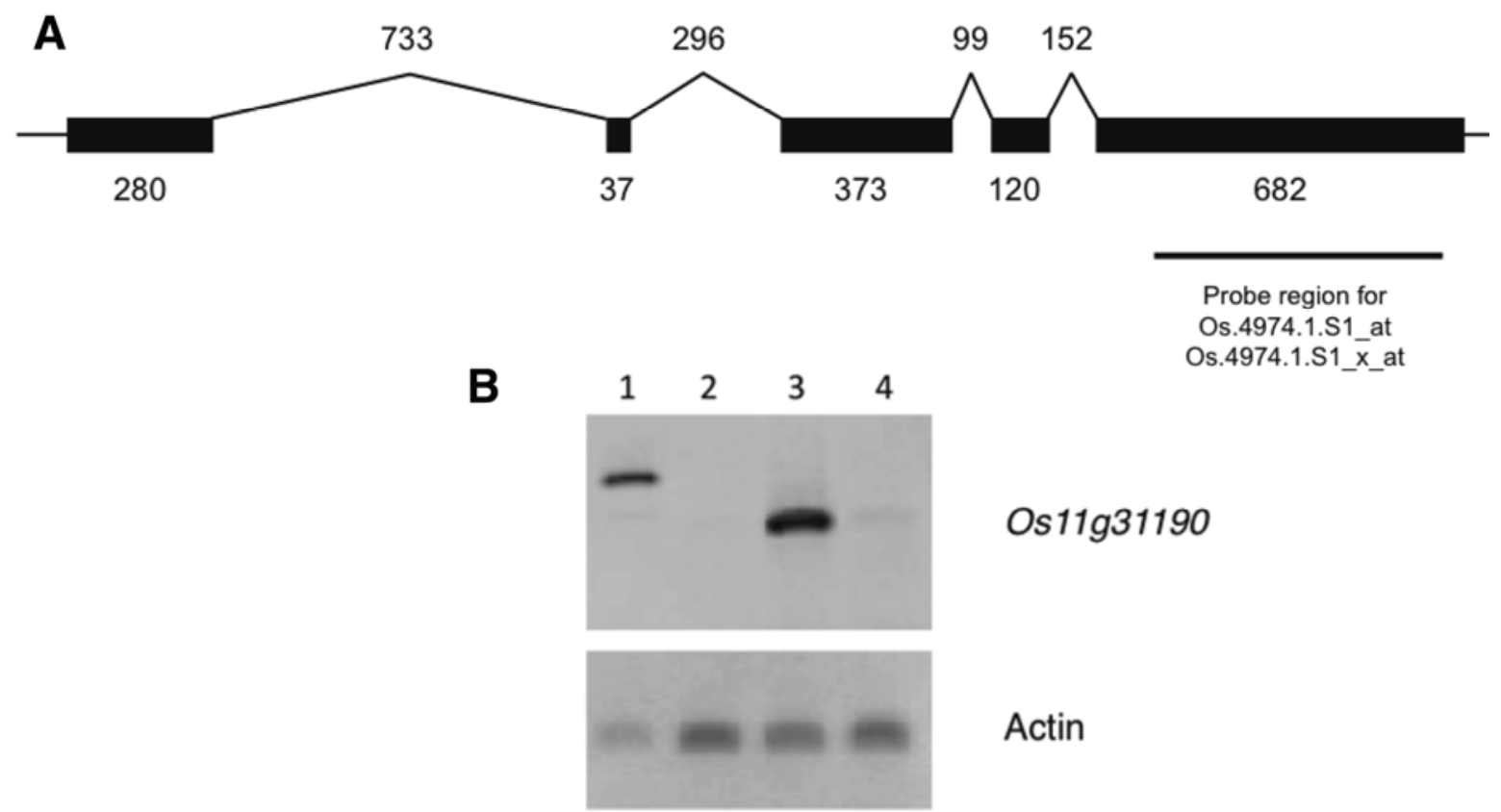

Fig. 6. TalC drives the induction of $N 3$ gene member Os $11 N 3$. A, Os $11 N 3$ is represented by the full-length cDNA AK101913. Exons are represented by solid dark boxes and introns as thin lines above. Numbers indicate the number of nucleotides. The $5^{\prime}$ and $3^{\prime}$ untranslated regions were inferred from the alignment of the genomic sequence with the cDNA sequence. Affymetrix probe set ID numbers are indicated below the diagram. B, Os $11 N 3$ is induced in a talC-dependent manner. Semiquantitative reverse transcription-polymerase chain reaction of Os11N3 (26 cycles) and actin (28 cycles) was performed with RNA purified $24 \mathrm{~h}$ postinfiltration of Nipponbare rice leaves with water (lane 2) and X. oryzae pv. oryzae strains BAI ${ }^{\mathrm{R}}$ (lane 3 ) and BAI $3^{\mathrm{R}} \Delta$ talC (lane 4$)$. Nipponbare genomic DNA (lane 1) was used as positive control. 
PXO86, respectively, representing different $X$. oryzae pv. oryzae lineages from Asia (Yang and White 2004). Earlier studies of our group had identified three new races of $X$. oryzae pv. oryzae originating from West Africa, A1 to A3, with strain BAI3 belonging to race $\mathrm{A} 1$, which is incompatible in the near-isogenic rice lines IRBB4, IRBB5, and IRBB7, but not in the parental line IR24. Surprisingly, analysis of the molecular diversity indicated that African $X$. oryzae pv. oryzae strains form a clearly separated genetic group distant to the Asian strains and more closely related to $X$. oryzae pv. oryzicola, the causal agent of bacterial leaf streak of rice (Gonzalez et al. 2007). Accordingly, phylogenetic analysis demonstrated that talC clusters together with tal genes of $X$. oryzicola pv. oryzicola BLS256 (Fig. 5). In addition, comparison of X. oryzicola pv. oryzicola BLS256 tal genes with those of $X$. oryzae pv. oryzae strains available in GenBank indicated a greater similarity among paralogues than among orthologues, suggesting that the expansion of tal gene families and repertoires in these two pathovars probably occurred after their divergence.

\section{$\mathrm{BAI}^{\mathrm{R}} \Delta t a l C$ is restricted for movement along the leaf but multiplies at the site of inoculation.}

Analysis of bacterial multiplication and movement in planta showed that $\mathrm{BAI} 3^{\mathrm{R}} \Delta$ talC was dramatically affected in its abil- ity to spread through the rice leaf blade. This behavior likely reflects the ability of the bacteria to move along the vascular tissues (Fig. 4C). Surprisingly, the mutant strain was still able to multiply at almost wild-type levels in the vicinity of the inoculation site (proximal 5-cm segment A). We hypothesize that, upon leaf-clip inoculation, $X$. oryzae pv. oryzae popula-

Table 2. Reactions of near-isogenic lines (NIL) IRBB4, IRBB5, IRBB7, and IRBB13 with single bacterial-resistance genes $(X a)$ against Xanthomonas oryzae pv. oryzae strains ${ }^{\mathrm{a}}$

\begin{tabular}{|c|c|c|c|c|c|}
\hline NIL & $X a$ gene & BAI3 & PXO99A & $\begin{array}{l}\text { PXO99 }^{A} \\
\text { pBBR1-5 }\end{array}$ & $\begin{array}{c}\text { PXO99 }^{\mathrm{A}} \\
\text { pBBR-13H5 }\end{array}$ \\
\hline IR24 & & $\mathrm{S}$ & $\mathrm{S}$ & $\mathrm{S}$ & $\mathrm{S}$ \\
\hline IRBB4 & Xa4 & $\mathrm{R}$ & $\mathrm{S}$ & $\mathrm{S}$ & $\mathrm{S}$ \\
\hline IRBB5 & $x a 5$ & $\mathrm{R}$ & $\mathrm{S}$ & $\mathrm{S}$ & $\mathrm{S}$ \\
\hline IRBB7 & Xa7 & $\mathrm{R}$ & $\mathrm{S}$ & $\mathrm{S}$ & $\mathrm{S}$ \\
\hline IRBB13 & $x a 13$ & $\mathrm{~S}$ & $\mathrm{R}$ & $\mathrm{R}$ & $\mathrm{R}$ \\
\hline
\end{tabular}

${ }^{\mathrm{a}}$ Six-week-old IRBB lines were leaf clip-inoculated with $X$. oryzae pv

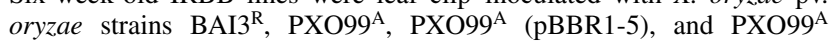
(pBBR-13H5). Resistance or susceptibility of rice plants to $X$. oryzae pv. oryzae is expressed in lesion lengths measured 14 days after inoculation. Resistant $(\mathrm{R})<5 \mathrm{~cm}$, moderately resistant $(\mathrm{MR})=5$ to $10 \mathrm{~cm}$, moderately susceptible (MS) $=10$ to $15 \mathrm{~cm}$, and susceptible (S) $>15 \mathrm{~cm}$. This experiment was reproduced three times, giving similar results.
A

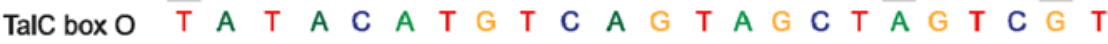

TalC NS NG NSHD NI NGNNNG HD NI NN N* NI NNHDNG NI NN N* HDNN NG

$\begin{array}{lllllllllllllll}0 & 1 & 2 & 3 & 4 & 5 & 6 & 7 & 8 & 9 & 10 & 11 & 11.5\end{array}$

Hax3 box T A C A C C C A A A C A T

Hax3 NI HD NI HDHDHDNSNSNS HD NI NG

B

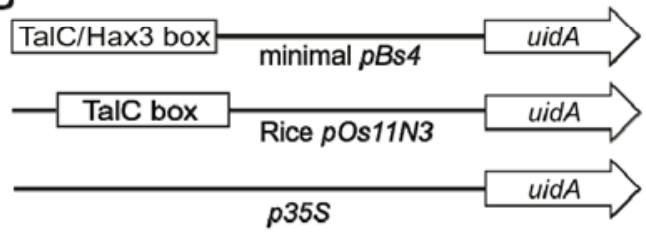

C

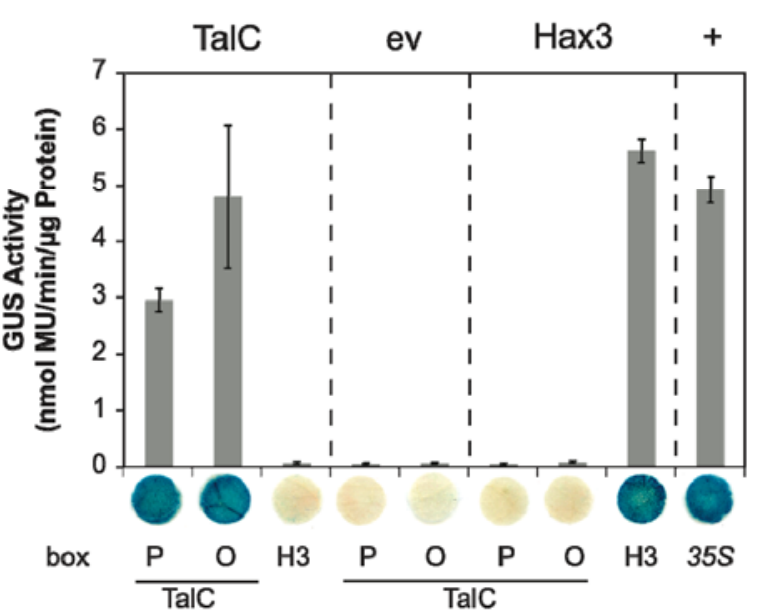

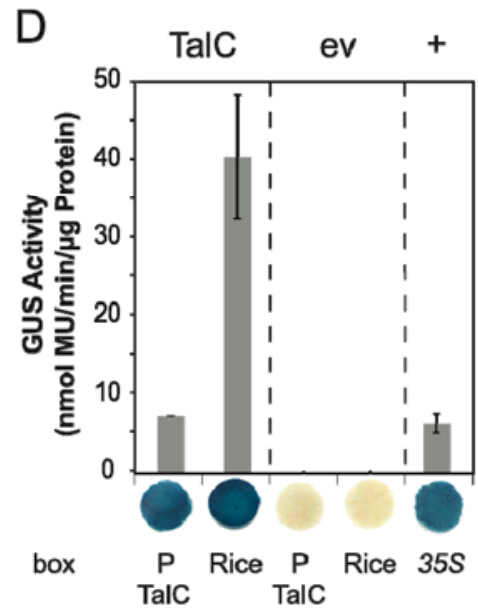

Fig. 7. The upstream region of $O s 11 N 3$ is transcriptionally activated by TalC. A, Amino acids 12 and 13 of the TalC and Hax 3 repeats and predicted target DNA specificities (TalC box P, native box; TalC box O, optimized box). B, TalC and Hax3 boxes cloned in front of the minimal Bs4 promoter and a 341 -bp fragment of the $O s 11 N 3$ region upstream of the coding region were cloned into a $\beta$-glucuronidase (GUS) reporter vector. $\mathbf{C}$, Specific inducibility of TalC box $\mathrm{O}$ and TalC box P by TalC. D, Specific inducibility of the Os11N3 341-bp upstream region (rice) by TalC. GUS reporter constructs were codelivered via Agrobacterium tumefaciens into Nicotiana benthamiana with 35S-driven talC, hax3, and empty T-DNA (ev) (error bars indicate standard deviation; $n=3$ ). $\mathrm{MU}=4$-methyl-umbelliferone. 35S::uidA (+) served as control. Leaf disks were stained with X-Gluc (5-bromo-4-chloro-3-indolyl- $\beta$-D-glucuronide). 
tions gain access to vascular tissues but also to the leaf mesophyll apoplasm. While a loss of talC probably impairs bacterial multiplication in the xylem, and therefore colonization of distal leaf segments (B and $\mathrm{C}$ ), bacteria having entered the mesophyll tissue may be able to multiply, although remaining restricted to tissues close to the inoculation site. This suggests that TalC is specifically required for the interaction with xylem parenchyma cells by either one or both suppressing vascularspecific defense responses or promoting the spread of the bacteria from local infection sites, i.e., by delivery of sufficient amounts of essential nutrients. Such tissue-specific virulence function of a TAL effector is a novel phenotype and has not yet been characterized for other xanthomonads. Interestingly, however, AvrAC $\mathrm{Xcc8004}_{\text {is an }}$ Avr protein from X. campestris $\mathrm{pv}$. campestris that was shown to elicit a hypersensitive response only when bacteria were inoculated into the vascular system by piercing the central veins of leaves ( $\mathrm{Xu}$ et al. 2008). In a conceptually comparable study, Iyer and associates (2008) reported on the effect of the recessive resistance gene $x a 5$ on $X$. oryzae pv. oryzae bacterial population dynamics. By analyzing bacterial growth and movement in isogenic rice lines containing $x a 5$ or $X a 5$, the authors showed that resistant plants restricted the progression of bacteria along the leaf without impairing their multiplication close to the inoculation site, similar to what we observed when comparing $\mathrm{BAI} 3^{\mathrm{R}}$ and $\mathrm{BAI} 3^{\mathrm{R}} \Delta$ talC. $X$. oryzae pv. oryzae infects leaves primarily by vascular colonization through hydathodes, in natural settings (Nino-Liu et al. 2006). Future experiments will, therefore, involve alternative inoculation methods, such as hydathode invasion (Hugouvieux et al. 1998), that better mimic the natural route of infection.

\section{TalC targets a gene of the $N 3$ nodulin family.}

By microarray experiments and sqRT-PCR comparing the transcriptomes of rice leaves challenged with $X$. oryzae $\mathrm{pv}$. oryzae $\mathrm{BAI} 3^{\mathrm{R}}$ versus $\mathrm{BAI} 3^{\mathrm{R}} \Delta$ talC, we identified several rice genes to be specifically induced by $X$. oryzae pv. oryzae $\mathrm{BAI}^{\mathrm{R}}$, thus most likely being under control of talC (Table 1). One of the most strongly induced genes was $O s 11 N 3$, a member of the MtN3/saliva family related to nodulin 3 (N3) protein of Medicago truncatula (White and Yang 2009). This family consists of approximately 20 members in rice and includes Os8N3, also known as Xa13 (Chu et al. 2006a). Interestingly, Os8N3 was identified by Yang and associates (2006) using similar microarray profiling experiments comparing the host response upon challenge with $\mathrm{PXO}^{\mathrm{A}}$ versus the mutant strain PXO99A ME2 defective in pthXol. Like talC, pthXol encodes a major virulence gene and activation of $O s 8 \mathrm{~N} 3$ transcription results in susceptibility of rice to $X$. oryzae pv. oryzae PXO99A. Os8N3 was therefore considered to be a $S$ gene (Yang et al. 2006). Our data demonstrate that Os $11 N 3$ is a direct target of TalC. Visual inspection of the Os11N3 upstream region revealed a potential DNA target box for TalC (Fig. 3), which was confirmed to be functional using GUS transient assays. Moreover, use of a 341-bp sequence upstream of OS11N3, including the TalC target box, led to even stronger enzymatic activity of the reporter (Fig. 7). Similar to our finding, another major virulence TAL effector, AvrXa7, was shown by electrophoretic mobility shift and GUS reporter assays to bind upstream of and to activate expression of Os11N3 (Römer et al. 2010). As depicted in Figure 3B, a DNA target box for AvrXa7 resides 38 bp downstream of the TalC box. Altogether, these data suggest functional convergence for virulence in the rice- $X$. oryzae pv. oryzae pathosystem whereby several strains with different geographical origins and belonging to different lineages rely on a single major virulence TAL, the function of which is to target members of the $N 3$ gene family.
How the function of $N 3$ genes relates to bacterial leaf blight disease of rice remains an open question. Os $8 N 3$ and $O S 11 N 3$ are probably functionally redundant disease-promoting genes, since the pthXo1-defective strain PXO99 ${ }^{\mathrm{A}} \mathrm{ME} 2$ can be complemented via the introduction of $a v r X a 7$ (Yang and White 2004). This finding suggests that lack of $O s 8 N 3$ induction can be overcome by avrXa7-dependent induction of Os11N3. Surprisingly, introduction of talC into $\mathrm{PXO}^{\mathrm{A}}{ }^{\mathrm{A}}$ did not restore virulence on $x a 13$ lines (Table 2), suggesting that the expected talC-dependent transcription activation of Os $11 \mathrm{~N} 3$ either did not occur or was insufficient to promote virulence. Similarly, introduction of pthXol or $a v r X a 7$ into $\mathrm{BAI} 3^{\mathrm{R}} \Delta t a l C$ did not restore virulence on susceptible rice lines (not shown). The molecular basis for this absence of complementation between major virulence TAL genes originating from Asia and Africa is so far unknown.

Finally, X. oryzae pv. oryzae $\mathrm{BAI} 3^{\mathrm{R}}$ is incompatible on the IRBB7 rice line, which contains the matching $\mathrm{X} a 7$ resistance gene (Gonzalez et al. 2007). This suggests that BAI3 ${ }^{\mathrm{R}}$ harbors avrXa7 activity. Our data show that $\mathrm{PXO} 99^{\mathrm{A}}$ expressing talC is not able to trigger $\mathrm{Xa7}$-mediated resistance (Table 2). Either this $a v r$ activity is repressed in $\mathrm{PXO} 99^{\mathrm{A}}$, possibly by other $\mathrm{T} 3 \mathrm{E}$, or another TAL effector of $\mathrm{BAI} 3^{\mathrm{R}}$ is involved, possibly related to the 4.2-kb BamHI fragment that was detected in Southern blots. Future analysis of the other BAI $3^{\mathrm{R}}$ tal members will help us to elucidate how virulence evolved in African strains and to which extent each tal gene contributes to compatible and incompatible interactions.

\section{MATERIALS AND METHODS}

\section{Bacterial strains and growth conditions.}

Bacterial strains used in this study were Escherichia coli DH5 $\alpha$ (Stratagene, La Jolla, CA, U.S.A.) and X. oryzae pv. oryzae strains BAI3 (Gonzalez et al. 2007) and PXO99 ${ }^{\mathrm{A}}$ (Hopkins et al. 1992). In order to enable BAI3 for triparental conjugation, rifampicin-resistant clones were selected upon plating on PSA medium (10 $\mathrm{g}$ of peptone, $10 \mathrm{~g}$ of sucrose, $1 \mathrm{~g}$ of glutamic acid, $16 \mathrm{~g}$ of agar per liter of $\mathrm{H}_{2} \mathrm{O}$ ) supplemented with $100 \mu \mathrm{g} / \mathrm{ml}$ of rifampicin. Each of five isolates showing resistance to rifampicin was inoculated into rice and was confirmed to be as pathogenic as the wild-type strain. One, referred to as $\mathrm{BAI} 3^{\mathrm{R}}$, was chosen for further experiments. E. coli cells were cultivated at $37^{\circ} \mathrm{C}$ in lysogenic broth (LB) medium, $X$. oryzae pv. oryzae strains at $28^{\circ} \mathrm{C}$ in PSA medium and Agrobacterium tumefaciens $\mathrm{GV} 3101$ at $28^{\circ} \mathrm{C}$ in $\mathrm{LB}$ medium. Plasmids were introduced into E. coli and Agrobacterium strains by electroporation and into $X$. oryzae pv. oryzae using pRK2073 as a helper plasmid in triparental mating (Figurski and Helinski 1979). Antibiotics were added in the medium at the following final concentrations: kanamycin, $50 \mu \mathrm{g} / \mathrm{ml}$; rifampicin, $100 \mu \mathrm{g} / \mathrm{ml}$; gentamycin, $20 \mu \mathrm{g} / \mathrm{ml}$; and spectinomycin, $50 \mu \mathrm{g} / \mathrm{ml}$.

\section{Plant material and plant inoculations.}

Experiments were performed under greenhouse conditions at $26^{\circ} \mathrm{C}$ and $80 \%$ relative humidity. Rice lines Nipponbare and Azucena were used for virulence assays, while line IR24 and near-isogenic rice lines IRBB4, IRBB5, IRBB13, and IRBB7 containing the resistance genes $X a 4, x a 5, x a 13$, and $X a 7$ respectively, were used for avirulence tests (Ogawa et al. 1987). Leaves of 3-week-old plants were infiltrated with a bacterial suspension resuspended at an optical density at $600 \mathrm{~nm}$ $\left(\mathrm{OD}_{600}\right)$ of 0.5 using a needleless syringe, as previously described (Reimers and Leach 1991). Leaf-clip inoculation was performed on 4- to 6-week-old rice plants using a bacterial suspension resuspended at an $\mathrm{OD}_{600}$ of 0.2 (Kauffman et al. 1973). Symptoms were scored by observation of water-soak- 
ing upon syringe infiltration and by measuring lesion lengths upon leaf-clip inoculation, 5 and 14 days postinoculation, respectively. Significance between treatments was assessed using the Tukey honest significant difference test for post-analysis of variance pair-wise comparisons, set at $5 \%(P<0.05)$. Nicotiana benthamiana plants were grown with $16 \mathrm{~h}$ of light, 40 to $60 \%$ humidity, at $23^{\circ} \mathrm{C}$ (day) and $19^{\circ} \mathrm{C}$ (night) in the greenhouse. Leaves of 5- to 7-week-old plants were inoculated with Agrobacterium strains using a needleless syringe. Inoculated plants were transferred to a Percival growth chamber (BioRad, Munich) with $16 \mathrm{~h}$ of light at $22^{\circ} \mathrm{C}$ (day) and $18^{\circ} \mathrm{C}$ (night).

\section{Generation of tal mutants.}

To construct plasmid pVO-155-tal, a 206-bp avrXa7 fragment was amplified by PCR using primers Tal-Ct-F $\left(5^{\prime}-\mathrm{GAA}\right.$ TCAATCGCCGCATTCCCGA-3') and Tal-Ct-R (5'-ACTCGA AGCCCGCGGTGGAACG-3') and pH81 (Hopkins et al. 1992) as DNA template. The amplification product was ligated into T-tailed pBluescript II KS(+) (Marchuk et al. 1990) and was subcloned as a 242-bp SalI/XbaI fragment into suicide vector pVO-155 (Oke and Long 1999), leading to pVO-155-tal. pVO155-tal was introduced into recipient strain $\mathrm{BAI} 3^{\mathrm{R}}$ by triparental mating, thus disrupting tal genes upon a single recombination event. Sixteen transconjugants obtained upon a single conjugation event were streaked twice consecutively on PSA medium supplied with rifampicin and kanamycin and were grown accordingly. To confirm the integration of pVO-155-tal into tal genes, nested PCR assays were performed by means of primers Tal-Ct-Fw2 (5'-GCGTTGGCCGCGTTGACCAA-3') and TalCt-Fw3 (5'-GCCGGATCAGGGCGAGATAACT-3'), and primers pVO-155-Rev (5'-TGTAGAAACCCCAACCCGTGAA-3') and pVO-155-Rev2 (5'-GCGCGTTACAAGAAAGCCGG-3'), annealing to sequences upstream of the 206-bp tal fragment carried by pVO-155-tal and in pVO-155, respectively. Primers Tal-Ct-Rev2 (5'-GGGGCCGCATCTTGTTCCCA-3') and TalCt-Rev3 (5'-CAGATCGTCCCTCCGACTGA-3') and primers pVO-155-FW (5'-GAGATCCCCAGCCCGCCTAATG-3') and pVO-155-FW2 (5'-CATGCCTGCAGGTCGAGATC-3') were used to analyze integration of pVO-155-tal downstream of the 206-bp tal fragment.

\section{Construction of $\mathrm{BAI}^{\mathrm{R}} \Delta$ hrc $C$.}

A $h r c C$ internal fragment (nucleotide 486 to 1,375 ) was obtained by PCR amplification using $\mathrm{BAI} 3^{\mathrm{R}}$ genomic DNA and was cloned into nonreplicative suicide plasmid pK18mob::sacB, yielding pK18mob::sacB-hrcC486-1375. Upon triparental conjugation, primary transformants were selected on GYE medium (20 g glucose, $10 \mathrm{~g}$ yeast extract per liter) supplemented with kanamycin. Next, kanamycin-resistant colonies were plated on GYE medium containing 5\% sucrose to select for second recombination. Colonies found to be sensitive to kanamycin and resistant to high sucrose concentration were assayed by PCR for disruption of $h r c C$, using primer hrcC-up (5'-TGAGACAT TCCCGGCTTTAC-3'), corresponding sequence upstream of the insert in pK18mob::sacB-hrcC486-1375, and primer hrcCdown (5'-TCAGGGCGACACCAATG-3'), which corresponds to the $3^{\prime}$ end of $h r c C$.

\section{In planta growth experiments.}

Infected leaves were collected at $0,4,8$, and 12 days after leaf-clip inoculation and were briefly rinsed in $70 \%$ ethanol, followed by submersion in sterile water for $10 \mathrm{~s}$. Leaves were cut into three segments of $5 \mathrm{~cm}$ from the apex, were put into 2-ml Eppendorf tubes containing two metallic beads $(\Phi=3 \mathrm{~mm})$, were frozen by submersion into liquid nitrogen, and were ground into a fine powder, using the Qiagen TissueLyser system (30 rounds per second for $2 \mathrm{~min}$ ). Ground material was resus- pended in $1 \mathrm{ml}$ of sterile water and 10- $\mu$ l drops of a dilution series were spotted onto PSA medium as triplicates. This experiment was performed three times.

\section{Southern blot hybridization.}

Standard procedures for Southern blots were utilized (Ausubel et al. 1988). Genomic DNA from X. oryzae pv. oryzae strains was extracted using Wizard genomic DNA purification kit (Promega, Madison, WI, U.S.A.), was digested with BamHI, and was migrated on a $0.8 \%$ agarose gel at $50 \mathrm{~V}$ for $36 \mathrm{~h}$. Filters were probed with a ${ }^{32} \mathrm{P}$-labeled 725-bp C-terminal $a v r X a 7$ fragment that was obtained by PCR using primers Tal-Ct-Fw2 and Tal-Ct-Rev2.

\section{Construction of a cosmid library and pBBR-13H5.}

A cosmid library of $X$. oryzae pv. oryzae $\mathrm{BAI} 3^{\mathrm{R}}$ genomic DNA was generated using the pWEB-TNC cosmid cloning kit (Epicentre Biotechnologies, Madison, WI, U.S.A.). Approximately 1,500 clones were obtained and stored. Dot-blot colony hybridization was performed using a ${ }^{32} \mathrm{P}$-labeled 725-bp C-terminal $a v r X a 7$ PCR product, leading to the identification of 51 positive clones. BamHI digestion of 18 potential tal-positive cosmids were analyzed by Southern-blot hybridization, thus identifying clones corresponding to the eight tal genes of strain BAI $3^{\mathrm{R}}$. Cosmid $13 \mathrm{H} 5$ was chosen for subcloning, as it was to contain a BamHI-hybridizing band corresponding to the expected molecular weight of talC. Cosmid $13 \mathrm{H} 5$ was digested with EcoRI and was directly ligated with EcoRI-linearized pBBR1MCS-5 (Kovach et al. 1995). Upon PCR-based screening, positive clones with a 8,901-kb insert fragment were identified and sequenced, yielding pBBR-13H5.

\section{Phylogenetic analysis.}

Amino-acid sequences of TAL effectors were retrieved from GenBank upon BlastP analysis, using TalC as query. When possible, proteins were chosen for representing the diversity of lineage and strain origin, especially among the Xanthomonas oryzae species. $\mathrm{N}$ - and $\mathrm{C}$-terminal regions were concatenated and aligned using ClustalW2. Sequence alignments were further processed manually to eliminate gaps due to indels. A neighbor-joining tree was constructed using PhyML with program SeaView version 4, and bootstrap analyses were based on 1,000 replicates. The tree was rooted using protein sequences of the non $-X$. oryzae pathovars as outgroup.

\section{Microarray experiments.}

Six fully expanded leaves of six 3-week-old independent individuals (cv. Nipponbare) were infiltrated with the tested strains $\left(\mathrm{OD}_{600}=0.5\right)$ and were pooled for RNA isolation at $24 \mathrm{~h}$ postinoculation. Total RNA was extracted using the RNeasy plant mini kit (Qiagen, Hilden, Germany), and on-column DNAse digestion was performed. All RNA samples were checked for their integrity on The Agilent 2100 bioanalyzer according to the Agilent Technologies (Waldbroon, Germany). Total RNA $(1 \mu \mathrm{g})$ was used to synthesize biotin-labeled cRNAs with the One-Cycle cDNA synthesis kit (Affymetrix, Santa Clara, CA, U.S.A.). The processed cRNA was used for hybridization to Affymetrix GeneChip Rice genome array on the Affymetrix GeneChip instrument system at the Institut National de la Recherche Agronomique Unité de Recherche en Génomique Végétale (Evry, France). The .raw CEL files were imported in R software for data analysis. All raw and normalized data are available through the CATdb database (AFFY_X. oryzae pv. oryzae_Rice; Gagnot et al. 2008) and from the Gene Expression Omnibus repository at the National Center for Biotechnology Information (Barrett and Edgar 2006), accession number GSE 19844. 
The data were normalized with the gcrma algorithm (Irizarry et al. 2003), available in the Bioconductor package (Gentleman et al. 2004). To determine differentially expressed genes, we performed a usual two group $t$-test that assumes equal variance between groups. The variance of the gene expression per group is a homoscedastic variance, where genes displaying extremes of variance (too small or too large) were excluded. The raw $P$ values were adjusted by the Bonferroni method, which controls the family wise error rate (Ge et al. 2003). A gene is declared differentially expressed if the Bonferroni $P$ value is less than 0.05. Similarity matches were provided at PLEXdb (Plant Expression database).

\section{SqRT-PCR experiments.}

RT-PCR experiments were performed using primers yielding a 300- to 400-bp product for each candidate target gene. RTPCR templates were produced as described for microarrays. RNA quality and quantity was estimated using a ND-1000 Nanodrop spectrophotometer. cDNA was synthesized with 1 $\mu \mathrm{g}$ of total RNA by means of the SuperScript first-strand synthesis system (Invitrogen, Carlsbad, CA, U.S.A.). Specific primers amplifying the actin transcript were used as control. Appropriate PCR cycle numbers specific to each gene and to the primer combination were determined by testing a wide range of cycle numbers and choosing one for which DNA amplification that was still in the exponential phase. PCR conditions appropriate for each gene and the corresponding primer pair sequences are available in Supplementary Table S1.

\section{TalC and GUS reporter constructs.}

The talC coding region was amplified by PCR from pBBR$13 \mathrm{H} 5$ and inserted into pENTR/D-TOPO (Invitrogen). Sequencing indicated no PCR errors. talC was transferred by LR recombination into pGWB6 (Nakagawa et al. 2007) to generate a green fluorescent protein-TalC fusion. Nuclear localization of the fusion protein was confirmed by confocal laser scanning microscopy. Derivatives of the TalC box were placed at the $5^{\prime}$ end of the minimal $B s 4$ promoter from tomato, using PCR, and were inserted into pENTR/D-TOPO (Invitrogen) as described previously (Boch et al. 2009). For GUS reporter constructs, a 341-bp fragment of the Os $11 N 3$ promoter region upstream of the coding region was subcloned into pENTR/D-TOPO. The predicted TalC box is located at position -319 to -297 . The promoter constructs were transferred by LR recombination into pGWB3 (Nakagawa et al. 2007) containing a promoterless uidA gene. All entry fragments were sequenced. Primers used for cloning of these constructs can be obtained upon request.

\section{GUS assays.}

GUS assays were done essentially as described previously (Boch et al. 2009). Briefly, Agrobacterium strains delivering TAL effector constructs and GUS reporter constructs were mixed 1:1 and were inoculated into Nicotiana benthamiana leaves with a total $\mathrm{OD}_{600}$ of 0.8 . At 2 days postinfiltration, leaf disks $(0.9 \mathrm{~cm}$ diameter) were sampled and GUS activity was determined. For qualitative GUS assays, leaf disks were incubated in X-Gluc (5-bromo-4-chloro-3-indolyl- $\beta$-D-glucuronide) staining solution, were destained in ethanol, and were dried. Quantitative GUS activities were determined using 4methyl-umbelliferyl- $\beta$-D-glucuronide as substrate. Proteins were quantified using Bradford assays (BioRad). Data are compiled from triplicate samples from different plants.

\section{ACKNOWLEDGMENTS}

We thank T. Mathieu for technical support in greenhouse experiments, H. Scholze and C. Kretschmer for constructs, and A. Bernut for setting up
sqRT-PCT experiments. We are grateful to G. Robin and B. Lafay for providing pK18mob::sacB-hrcC486-1375 and help for phylogeny analysis, respectively. Y. Yu was supported by a doctoral fellowship awarded by the Institut de Recherche pour le Développement (IRD, Département Soutien et Formation). This project was supported by a grant from IRD (action initiative DURBio, Département Ressources Vivant), the 973 Program of the Ministry of Science and Technology of China (2006CB101902), and the Open Project of the Key Laboratory of Ministry of Education for Microbial and Plant Genetic Engineering (J0602).

\section{LITERATURE CITED}

Ausubel, F. M., Brent, R., Kingston, R. E., Moore, D. D., Seidman, J. G., and Smith, J. A. 1988. Current Protocols in Molecular Biology. John Wiley \& Sons, New York.

Barrett, T., and Edgar, R. 2006. Mining microarray data at NCBI's Gene Expression Omnibus (GEO)*. Method Mol. Biol. 338:175-190.

Boch, J., and Bonas, U. 2010. Xanthomonas AvrBs3 family-type III effectors: Discovery and function. Annu. Rev. Phytopathol. 8:419-436.

Boch, J., Scholze, H., Schornack, S., Landgraf, A., Hahn, S., Kay, S., Lahaye, T., Nickstadt, A., and Bonas, U. 2009. Breaking the code of DNA binding specificity of TAL-type III effectors. Science 326:1509-1512.

Bogdanove, A. J., Schornack, S., and Lahaye, T. 2010. TAL effectors: Finding plant genes for disease and defense. Curr. Opin. Plant Biol. 13:394-401.

Bonas, U., Stall, R. E., and Staskawicz, B. 1989. Genetic and structural characterization of the avirulence gene avrBs 3 from Xanthomonas campestris pv. vesicatoria. Mol. Gen. Genet. 218:127-136.

Chu, Z., Fu, B., Yang, H., Xu, C., Li, Z., Sanchez, A., Park, Y., Bennetzen, J., Zhang, Q., and Wang, S. 2006a. Targeting xa13, a recessive gene for bacterial blight resistance in rice. Theor. Appl. Genet. 112:455-461.

Chu, Z., Yuan, M., Yao, J., Ge, X., Yuan, B., Xu, C., Li, X., Fu, B., Li, Z., Bennetzen, J. L., Zhang, Q., and Wang, S. 2006b. Promoter mutations of an essential gene for pollen development result in disease resistance in rice. Genes Dev. 20:1250-1255.

Figurski, D. H., and Helinski, D. R. 1979. Replication of an origin-containing derivative of plasmid RK2 dependent on a plasmid function provided in trans. Proc. Natl. Acad. Sci. U.S.A. 76:1648-1652.

Flor, H. H. 1971. Current status of gene-for-gene concept. Annu. Rev. Phytopathol. 9:275-296.

Gagnot, S., Tamby, J. P., Martin-Magniette, M. L., Bitton, F., Taconnat, L., Balzergue, S., Aubourg, S., Renou, J. P., Lecharny, A. and Brunaud, V. 2008. CATdb: A public access to Arabidopsis transcriptome data from the URGV-CATMA platform. Nucleic Acids Res. 36(Database issue): D986-D990.

Ge, Y., Dudoit, S., and Speed, T. P. 2003. Resampling-based multiple testing for microarray data analysis. TEST 12:1-44.

Gentleman, R. C., Carey, V. J., Bates, D. M., Bolstad, B., Dettling, M., Dudoit, S., Ellis, B., Gautier, L., Ge, Y., Gentry, J., Hornik, K., Hothorn, T., Huber, W., Iacus, S., Irizarry, R., Leisch, F., Li, C., Maechler, M., Rossini, A. J., Sawitzki, G., Smith, C., Smyth, G., Tierney, L., Yang, J. Y., and Zhang, J. 2004. Bioconductor: Open software development for computational biology and bioinformatics. Genome Biol. 5:R80.

Gonzalez, C., Szurek, B., Manceau, C., Mathieu, T., Séré, Y., and Verdier, V. 2007. Molecular and pathotypic characterization of new Xanthomonas oryzae strains from west africa. Mol. Plant-Microbe Interact. 20:534-546.

Gu, K., Yang, B., Tian, D., Wu, L., Wang, D., Sreekala, C., Yang, F., Chu, Z., Wang, G.-L., White, F. F., and Yin, Z. 2005. $R$ gene expression induced by a type-III effector triggers disease resistance in rice. Nature 435:1122-1125.

Hopkins, C. M., White, F. F., Choi, S. H., Guo, A., and Leach, J. E. 1992. Identification of a family of avirulence genes from Xanthomonas oryzae pv. oryzae. Mol. Plant-Microbe Interact. 5:451-459.

Hugouvieux, V., Barber, C. E., and Daniels, M. J. 1998. Entry of Xanthomonas campestris pv. campestris into hydathodes of Arabidopsis thaliana leaves: A system for studying early infection events in bacterial pathogenesis. Mol. Plant-Microbe Interact. 11:537-543.

Irizarry, R. A., Hobbs, B., Collin, F., Beazer-Barclay, Y. D., Antonellis, K J., Scherf, U., and Speed, T. P. 2003. Exploration, normalization, and summaries of high density oligonucleotide array probe level data. Biostatistics 4:249-264.

Kauffman, H. E., Reddy, A. P. K., Hsieh, S. P. H., and Merca, S. D. 1973. Improved technique for evaluating resistance of rice varieties to Xanthomonas oryzae. Plant Dis. Rep. 57:537-541.

Kay, S., Hahn, S., Marois, E., Hause, G., and Bonas, U. 2007. A bacterial effector acts as a plant transcription factor and induces a cell size regulator. Science 318:648-651.

Kovach, M., Elzer, P., Hill, D., Robertson, G., Farris, M., Roop, R. M., and 
Peterson, K. 1995. Four new derivatives of the broad-host-range cloning vector pBBR1MCS, carrying different antibiotic-resistance cassettes. Gene 166:175-176.

Lyer-Pascuzzi, A., Jiang, H., Huang, L., and McCouch, S. 2008. Genetic and functional characterization of the rice bacterial blight disease resistance gene xa5. Phytopathology 89:289-295.

Marchuk, D., Drumm, M., Saulino, A., and Collins, F. S. 1990. Construction of T-vectors, a rapid and general system for direct cloning of unmodified PCR products. . Nucleic Acids Res. 19:1154.

Marois, E., Van den Ackerveken, G., and Bonas, U. 2002. The Xanthomonas type III effector protein AvrBs3 modulates plant gene expression and induces cell hypertrophy in the susceptible host. Mol. Plant-Microbe Interact. 15:637-646.

Moscou, M. J., and Bogdanove, A. J. 2009. A simple cipher governs DNA recognition by TAL effectors. Science 326:1501.

Nakagawa, T., Kurose, T., Hino, T., Tanaka, K., Kawamukai, M., Niwa, Y., Toyooka, K., Matsuoka, K., Jinbo, T., and Kimura, T. 2007. Develop-

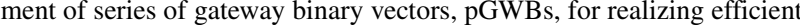
construction of fusion genes for plant transformation. J. Biosci. Bioeng. 104:34-41.

Nino-Liu, D. O., Ronald, P. C., and Bogdanove, A. J. 2006. Xanthomonas oryzae pathovars: Model pathogens of a model crop. Mol. Plant Pathol. 7:303-324.

Ogawa, T., Busto, G. A., Yamamoto, T., Khush, G. S., and Mew, T. W. 1987. Group of rice varieties based on the reaction to four Philippine races of Xanthomonas campestris pv. oryzae. Rice Genetics Newsl. 3:84-86.

Oke, V., and Long, S. R. 1999. Bacterial genes induced within the nodule during the Rhizobium-legume symbiosis. Mol. Microbiol. 32:837-849.

Reimers, P. J., and Leach, J. E. 1991. Race specific resistance to Xanthomonas oryzae pv. oryzae conferred by bacterial blight resistance gene $\mathrm{Xa}-10$ in rice (Oryza sativa) involves accumulation of a lignin-like substance in host tissues. Physiol. Mol. Plant Pathol. 38:39 -55.

Römer, P., Hahn, S., Jordan, T., Strauss, T., Bonas, U., and Lahaye, T. 2007. Plant pathogen recognition mediated by promoter activation of the pepper Bs3 resistance gene. Science 318:645-648.

Römer, P., Recht, S., Strauß, T., Elsaesser, J., Schornack, S., Boch, J., Wang, S., and Lahaye, T. 2010. Promoter elements of rice susceptibility genes are bound and activated by specific TAL effectors from the bacterial blight pathogen, Xanthomonas oryzae pv. oryzae. New Phytol. 187:1048-1057.

Sugio, A., Yang, B., Zhu, T., and White, F. F. 2007. Two type III effector genes of Xanthomonas oryzae pv. oryzae control the induction of the host genes $O s T F I I A \gamma 1$ and $O s T F X 1$ during bacterial blight of rice. Proc. Natl. Acad. Sci. U.S.A. 104:10720-10725.

Swarup, S., De Feyter, R., Brlansky, R. H., and Gabriel, D. W. 1991. A pathogenicity locus from Xanthomonas citri enables strains from several pathovars of Xanthomonas campestris to elicit canker-like lesions on citrus. Phytopathology 81:802-809.

Swarup, S., Yang, Y., Kingsley, M. T., and Gabriel, D. W. 1992. An Xanthomonas citri pathogenicity gene, pthA, pleiotropically encodes gratuitous avirulence on nonhosts. Mol. Plant-Microbe Interact. 5:204-213.

White, F., and Yang, B. 2009. Host and pathogen factors controlling the rice interaction. Plant Physiol. 150:1677-1686.

White, F. F., Potnis, N., Jones, J. B., and Koebnik, R. 2009. The type III effectors of Xanthomonas. Mol. Plant Pathol. 10:749-766.

Xu, R. Q., Blanvillain, S., Feng, J. X., Jiang, B. L., Li, X. Z., Wei, H. Y., Kroj, T., Lauber, E., Roby, D., Chen, B., He, Y. Q., Lu, G. T., Tang, D. J., Vasse, J., Arlat, M., and Tang, J. L. 2008. AvrAC(Xcc8004), a type III effector with a leucine-rich repeat domain from Xanthomonas campestris pathovar campestris confers avirulence in vascular tissues of Arabidopsis thaliana ecotype Col-0. J. Bacteriol. 190:343-355.

Yang, B., and White, F. F. 2004. Diverse members of the AvrBs3/PthA family of type III effectors are major virulence determinants in bacterial blight disease of rice. Mol. Plant-Microbe Interact. 17:1192-1200.

Yang, B., Sugio, A., and White, F. F. 2006. Os $8 N 3$ is a host disease-susceptibility gene for bacterial blight of rice. Proc. Natl. Acad. Sci. U.S.A. 103:10503-10508.

\section{AUTHOR-RECOMMENDED INTERNET RESOURCES}

ClustalW2 software: www.ebi.ac.uk/Tools/clustalw2/index.htm

National Center for Biotechnology Information website: www.ncbi.nlm.nih.gov

PLEXdb (Plant Expression database): www.plexdb.org/index.php 